Barroso Bermejo, R., Bueno Ramírez, P., Balbín Behrmann, R. de, González Martín, A. y Rojas Rodríguez-Malo, J. M. (2018): “Inhumaciones en urna cerámica de la Edad del

Bronce en la cuenca media y alta del Tajo: una perspectiva comparativa", Spal 27.1: 13-30. DOI: http://dx.doi.org/10.12795/spal.2018i27.01

\title{
INHUMACIONES EN URNA CERÁMICA DE LA EDAD DEL BRONCE EN LA CUENCA MEDIA Y ALTA DEL TAJO: UNA PERSPECTIVA COMPARATIVA
}

\author{
BRONZE AGE INHUMATIONS IN CERAMIC URN IN THE MIDDLE AND \\ UPPER TAGUS BASIN: A COMPARATIVE POINT OF VIEW
}

\author{
ROSA BARROSO BERMEJO \\ Área de Prehistoria. Facultad de Filosofía y Letras. Universidad de Alcalá de Henares. C/ Colegios 2, 28801, Alcalá de Henares, Madrid \\ Correo-e: rosa.barroso@uah.es. ORCID: https://orcid.org/0000-0003-3129-4497 \\ PRIMITIVA BUENO RAMÍREZ \\ Área de Prehistoria. Facultad de Filosofía y Letras. Universidad de Alcalá de Henares. C/ Colegios 2, 28801, Alcalá de Henares, Madrid \\ Correo-e: p.bueno@uah.es. ORCID: https://orcid.org/0000-0001-8958-8928 \\ RODRIGO DE BALBÍN BEHRMANN \\ Área de Prehistoria. Facultad de Filosofía y Letras. Universidad de Alcalá de Henares. C/ Colegios 2, 28801, Alcalá de Henares, Madrid \\ Correo-e: rodrigo.balbín@uah.es. ORCID: https://orcid.org/0000-0002-3947-5308 \\ ARMANDO GONZÁLEZ MARTÍN \\ Laboratorio de Poblaciones del Pasado. Departamento de Biología. Facultad de Ciencias. Universidad Autónoma de Madrid. \\ Correo-e: armando.gonzalez@uam.es. ORCID: https://orcid.org/0000-0001-9216-1220 \\ JUAN MANUEL ROJAS RODRÍGUEZ-MALO \\ Juan Manuel Rojas arqueología S.L. \\ Correo-e: jmrojasrodriguez@yahoo.es. ORCID: https://orcid.org/0000-0002-9699-5246
}

Resumen: Se aborda el tema de los enterramientos prehistóricos en urnas en el valle interior del río Tajo. Los caracterizamos a partir de los enterramientos conocidos hasta el momento en la zona y tres más inéditos procedentes del yacimiento de Las Mayores (Toledo), de los que hemos obtenidos recientes datos arqueométricos. Con la información resultante reflexionamos sobre su relación con otros ámbitos peninsulares, especialmente el argárico, donde tienen amplia representación, y sobre su identificación dentro de la secuencia zonal, siendo característicos de la Edad del Bronce pero ajenos a las comunidades Protocogotas. Los enterramientos en pithoi tienen escaso arraigo en el interior peninsular, mostrando, aun así, una enorme variabilidad que impide ver en ellos consideraciones sociales más allá de los valores comprensibles dentro del reducido ámbito familiar, que es el dominante en los enterramientos de la Edad del Bronce en la zona.

Palabras clave: Península ibérica; valle del Tajo; Edad del Bronce; enterramientos; pithos; C14.
Abstract: Prehistoric urn burials in the inland Tagus valley are characterised through the known examples in the area and three new ones at the site of Las Mayores (Toledo), for which archaeometric data have recently been obtained. The information obtained allows a reflection, first on their relationship with other parts of Iberia, especially the Argaric world, where such burials are well known. In second place, their identification within the regional sequence is assessed, as they are characteristic of the Bronze Age but foreign to ProtoCogotas communities. Pithoi burials did not enjoy a tradition in inland Iberia and their great variability does not allow social considerations at the community level. This practice is only comprehensible within the small family circles of the segmentary societies that characterised the Bronze Age in the area.

Keywords: Iberian Peninsula; Tagus valley; Bronze Age; burials; pithos; Radiocarbon. 


\section{INTRODUCCIÓN}

Los enterramientos de la Edad del Bronce, hasta hace poco minoritarios en el valle interior del río Tajo, sector de Castilla-La Mancha y la Comunidad de Madrid, han tenido un importante incremento en los últimos años. Hemos pasado de la escasa treintena de finales del siglo pasado (Blasco 1997) a quintuplicarse su número (Aliaga 2012; Barroso et al. 2014; Pérez Villa 2015). Incluso contamos ya con una aproximación demográfica que se enfrenta al siempre repetido escaso contingente de enterramientos meseteños, concluyendo con la existencia de una población real, sin restricciones diferenciales de acceso a la tumba (Pérez Villa 2015: 77). Individuos de ambos sexos y todas las edades forman, por tanto, una población representativa que aun así podría diferir de la población original por cuestiones muy diversas. Es el caso de los problemas de conservación, la existencia de enterramientos fuera de los entornos intervenidos, en especial allí donde las excavaciones son parciales, o la combinación de distintas prácticas funerarias.

Frente a la etapa calcolítica anterior, todos estos trabajos coinciden en caracterizar los contextos funerarios de la Edad del Bronce por la individualidad de los enterramientos y el uso de fosas a modo de tumbas (Pérez Villa 2015: 115; Barroso 2016). Los enterramientos individuales no son los únicos, pero sí tienen una presencia mayoritaria. Respecto a las fosas, utilizadas como contenedores funerarios desde mucho antes, será en la Edad del Bronce cuando se ratifiquen como el tipo de tumba predilecto. La frecuencia con que se abren nichos en las paredes de las fosas o el uso de urnas cerámicas son algunas de las pocas novedades de un comportamiento funerario que, sobre todo, puede caracterizarse de continuista a lo largo de la Edad del Bronce.

En ese tipo de enterramiento en urna funeraria o pithos queremos fijarnos aquí. El término griego alude a grandes vasijas globulares u ovoides que por su tamaño están relacionadas, en primera instancia, con el almacenamiento y la conservación de alimentos, pudiendo también recoger depósitos funerarios. En realidad, estamos ante recipientes de muy distinta tipología y tamaño que, entre otros muchos usos para los que fueron fabricados, ejercen una función funeraria. Su baja representación dentro de la cuenca del Tajo (Pérez Villa 2015: 120) los hace singulares y escasamente estudiados, a pesar de asociarse a un grupo de edad, el infantil, que dada la alta mortalidad esperable en toda población antigua, debería ser notable.

\section{OBJETIVOS Y BASE DE ANÁLISIS}

Partimos de los enterramientos en urna de la Edad del Bronce conocidos en el Tajo, que hasta el momento no cuentan con una caracterización conjunta. A esta documentación aportamos el análisis de tres enterramientos inéditos localizados en el yacimiento de Las Mayores (Numancia de la Sagra, Toledo) dentro de un proyecto conjunto de la Universidad de Alcalá y la Junta de Comunidades de Castilla-La Mancha. Contamos para su estudio con las fotografías de campo, dibujos de plantas y secciones de las estructuras, así como el inventario general de los materiales que fueron depositados en el Museo de Santa Cruz (Toledo). El análisis morfológico de estos materiales, la obtención de fechas absolutas, el estudio bioarqueológico de huesos humanos y fauna así como el procesado de parte del sedimento conservado de las tumbas, nos permiten incorporar datos de primera mano a este tipo de contextos. El estudio antropológico ha sido realizado en el Laboratorio de Poblaciones del Pasado de la Universidad Autónoma de Madrid, siguiendo la metodología ya expuesta en trabajos anteriores (González Martín 2008). En el estudio arqueozoológico, para la identificación taxonómica, el cálculo de NR, la adscripción del NMI, la observación de los patrones de edad y el cálculo de edades, sus autores utilizaron los criterios y obras de referencia expuestos en trabajos anteriores (Yravedra y Estaca 2013: 173-174).

Una vez caracterizados, valoraremos su presencia y significado fuera de su territorio de referencia peninsular, el Sureste, donde al contrario que en el Tajo son ampliamente conocidos en relación al contexto argárico. Somos conscientes de que las prácticas funerarias no pueden entenderse aisladas unas de otras o sin entrelazarse con una buena información de los asentamientos, de las unidades de habitación, de trabajo o almacenamiento que aún tienen muy pocos datos en el Tajo. Por eso no es tanta nuestra pretensión de interpretación histórica de las comunidades de la Edad del Bronce en las que se inscriben, como la de generar datos solventes que permitan avanzar en algunos de los frentes interpretativos abiertos.

Uno de ellos, sin duda, es la caracterización de las primeras comunidades de la Edad del Bronce, aquellas que protagonizan el proceso de cambio respecto a las comunidades calcolíticas anteriores. La falta de estudios en profundidad de un poblamiento de estructuras en negativo, solo en apariencia inamovible desde el Neolítico a finales de la Edad del Bronce, ha forjado en el Tajo una secuencia guiada por los tipos cerámicos 


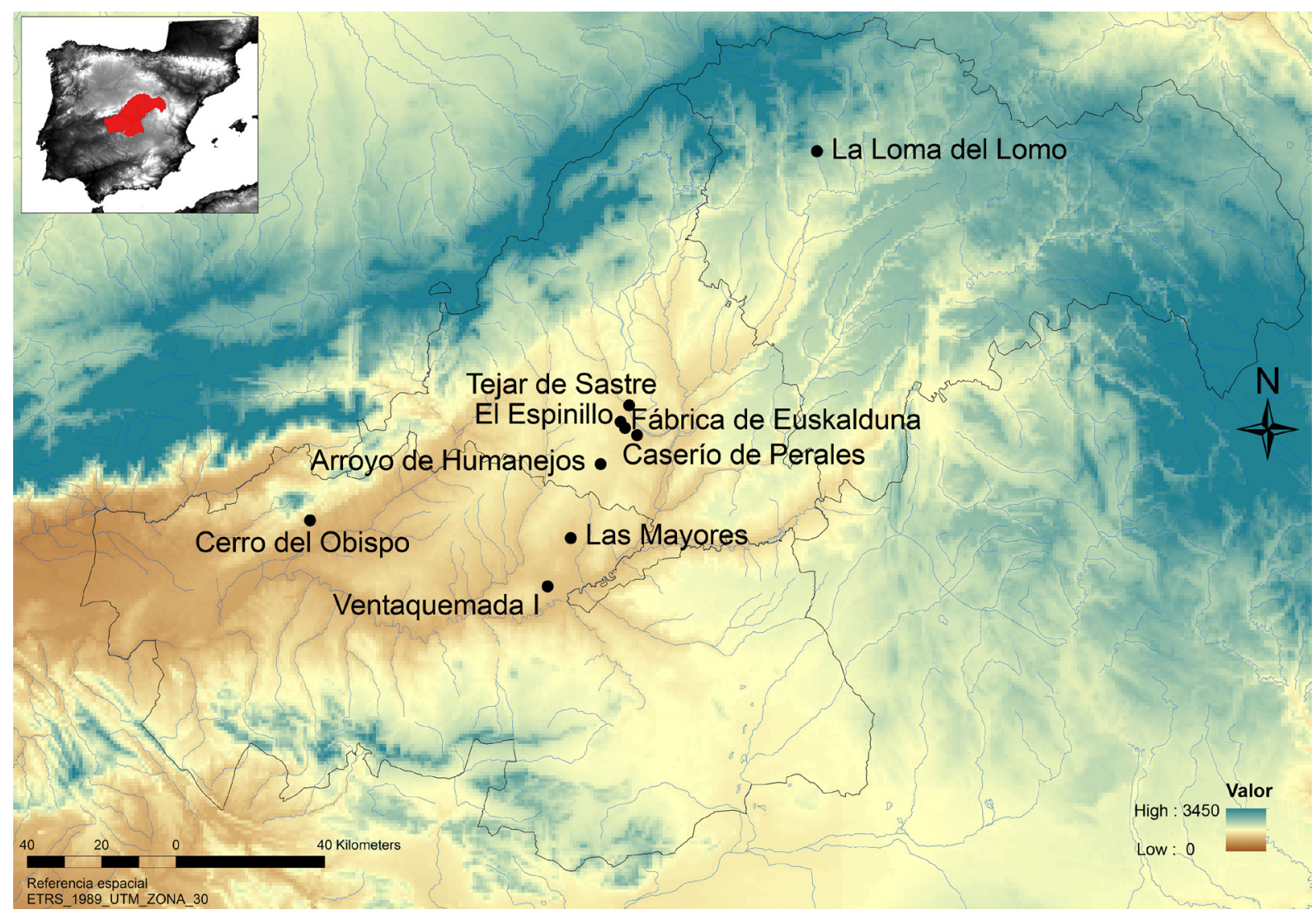

Figura 1. Mapa de la Península Ibérica con la localización del área de estudio y detalle de los yacimientos con enterramientos en urnas localizados en el Tajo.

diagnósticos (Pérez Villa 2015: 30-34). Cerámicas campaniformes o Cogotas han servido para delimitar, respectivamente, comunidades de afinidad calcolítica que se extienden por los convencionales comienzos de la Edad del Bronce y las que se extienden por los no menos convencionales Bronce Medio y Final. Entre y sobre ellas, existe un Bronce "Clásico" (Díaz del Río 2001: 52) de difícil demarcación material, pues se caracteriza por cerámicas lisas o decoradas de escasa relevancia dadas sus sencillas impresiones o motivos plásticos. A pesar de contar con escasas fechas absolutas, las fases basadas en clasificaciones materiales y divisiones temporales han primado sobre la idea de continuidad.

Los enterramientos en vasijas se identifican con claridad como de la Edad del Bronce por impropios del ámbito campaniforme (Aliaga y Megías 2011: 168) y a su vez desligados de Protocogotas (Blasco 1997: 187), lo que los convierte en un interesante elemento para repasar aquí algunos de los problemas que suponen estas fases y sus indicadores cerámicos.

\section{LOS DATOS DISPONIBLES}

\subsection{El registro previo}

La primera noticia sobre enterramientos en pithoi nos sitúa en los areneros del Manzanares. Será Pérez de Barradas el que, dando a conocer los materiales postpaleolíticos de la colección Bento, señale la aparición, en 1927, de una sepultura argárica de un niño en vasija en el yacimiento de Tejar del Sastre (Pérez de Barradas 1936: 48 y 73). Desde entonces los hallazgos se han venido repitiendo tanto en Madrid como en el resto de las provincias que recorre el Tajo en su curso alto y medio, Guadalajara y Toledo (fig. 1).

En el mismo ámbito, sobre una terraza del Manzanares se localizan los hallazgos de El Espinillo, un poblado de fondos de cabaña excavado en los años 1990 (Baquedano et al. 2000) que a su vez es prolongación del yacimiento de La Fábrica de Euskalduna (Almagro 1960). Las excavaciones localizaron un fondo (101B), cortado en los trabajos de desmonte, en el que 


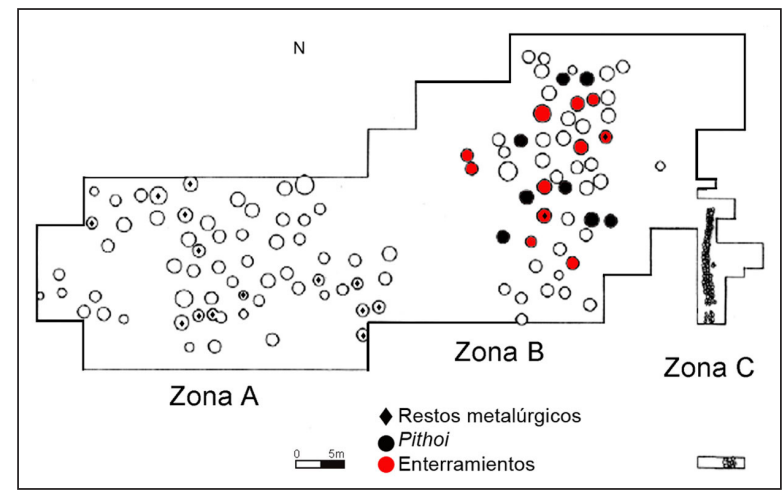

Figura 2. Plano del área excavada en La Loma del Lomo (Cogolludo, Guadalajara) con la situación de los enterramientos localizados, a partir de Valiente 2001: Figs. 201 y 202

se encontraron algunos restos óseos de una mujer adulta (Lorenzo y Borobia 2000: 137). El hallazgo próximo, en superficie, de un fragmento de un recipiente de gran tamaño lleva a interpretar el conjunto como una probable "inhumación secundaria en jarra" (Baquedano et al. 2000: 27). Hay que tomar con precaución esta propuesta, igual que ocurre en el enterramiento del fondo 20 de El Caserío de Perales. En esta ocasión, los restos pésimamente conservados de un varón de entre 20-25 años se encontraron divididos en cuatro partes que mantenían su conexión. Los fragmentos de recipientes cerámicos que servían de base y cubrición a los restos se interpretan como los contenedores funerarios. En cualquier caso, fue imposible reconstruirlos completos, precisar si el cuerpo fue desmembrado para su primer enterramiento o si se trataba de una inhumación secundaria. El material documentado era escasamente significativo y solo por su proximidad a otras fosas con materiales Protocogotas se admitió esta adscripción (Blasco et al. 1991: 68).

A unos $400 \mathrm{~m}$ al sureste del Espinillo se realizaron en los años 1950 trabajos relacionados con la construcción de la fábrica de Euskalduna y posteriormente la de Transfesa. Durante la recogida de materiales y excavación de varios fondos se encontraron los restos de un enterramiento de dos individuos. La adherencia de algunos huesos a fragmentos cerámicos de tinajas grandes hace pensar que al menos uno de ellos fue enterrado en ellas (Almagro 1960: 19). Todos estos datos del Manzanares, que ciertamente configuran una documentación muy parcial de la capital, se verán enriquecidos por registros recientes como es el caso del enterramiento de Arroyo de Humanejos-Km 24 (Vega et al. 2014).

Bien distinta es la aportación de Guadalajara. El poblado de La Loma del Lomo, al norte de la provincia, cuenta, hasta el momento, con el conjunto más numeroso de enterramientos en vasijas del Tajo, ocho de los 23 enterramientos localizados en él. Disponemos de descripciones estratigráficas de las estructuras, de los restos materiales y el análisis antropológico de todos los enterramientos (Valiente 1987 y 1992). De los 8 que nos ocupan llegó a determinarse el sexo de dos de ellos, un infantil y un adulto, ambos varones. Todos ellos se agrupan en el sector B del yacimiento (fig. 2), en unos $350 \mathrm{~m}^{2}$, intercalándose los enterramientos en vasijas con el resto de las inhumaciones sin contenedor cerámico y otros tantos depósitos faunísticos. De hecho, resulta significativo que en uno de los hoyos se localizara una cazuela cubriendo los restos de un suido neonato (Valiente 1992: 130). La zona se caracteriza como área de vivienda y almacenaje frente al sector $\mathrm{A}$, determinado como área de actividad metalúrgica por la gran cantidad de residuos y testimonios metálicos de sus fosas (Valiente 2001: 258259). No se documenta en sentido estricto ninguna casa, pero se asume que las fosas funerarias se integraban con distintos usos dentro de la vivienda.

La primera referencia de pithoi en la provincia de Toledo procede del Cerro del Obispo en Castillo de Bayuela (Gil et al. 1988; Menéndez et al. 1988). Las excavaciones realizadas en los años 1980 describen el yacimiento como una necrópolis de inhumaciones en pithoi colocados en cistas de piedra con tapa de cerámica, ajuares de cerámicas y ofrendas de porciones de ovicaprinos y vacuno. Se señala el hallazgo de cinco sepulturas pero no se individualizan bien los materiales asociados a cada una de ellas. Ciertamente los datos del yacimiento son tan escuetos que poco puede valorarse, salvo la relación con cistas que también se reproduce en Villalmanzo, una de las primeras referencias a los enterramientos en vasija en la Meseta Norte (Delibes 1971).

La documentación de la provincia se ha ampliado con el poblado de Ventaquemada I, Olías del Rey. El poblado posee un enterramiento de un infantil (UE 140), de menos de 6 meses, localizado en un recipiente a su vez inserto en un nicho lateral abierto en una de las estructuras (Pérez Villa 2015: 243). Otro de los enterramientos en nicho de un individuo de edad y sexo indeterminado (E-670) fue cerrado con un gran pithos fragmentado a modo de pared.

\subsection{Nuevos datos: Enterramientos de Las Mayores (Numancia de la Sagra, Toledo)}

En 2006 se realizaron excavaciones en el yacimiento toledano de Las Mayores, al noreste de la provincia. El poblado se localiza sobre un paisaje llano y su 

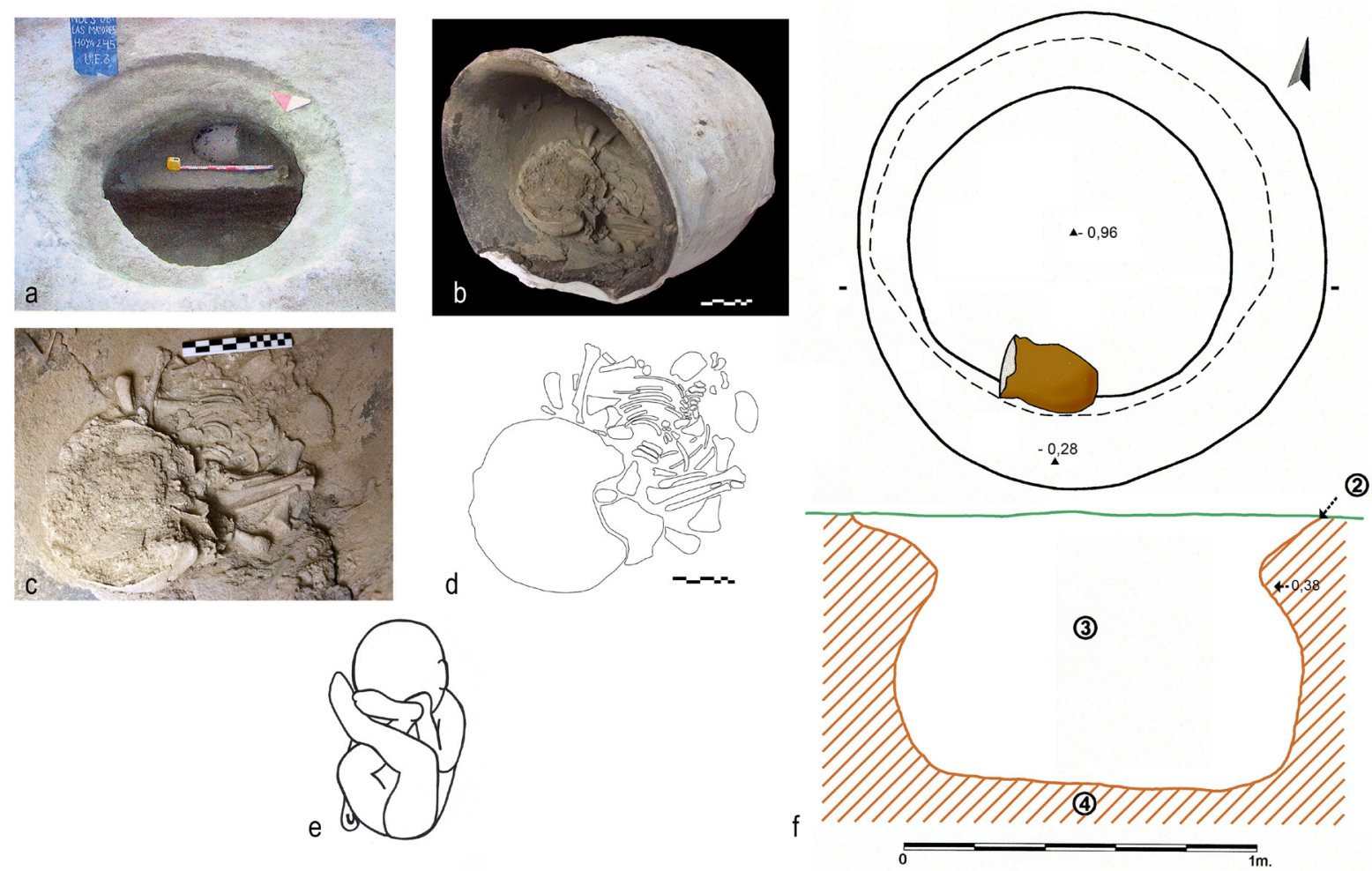

Figura 3. Fosa 245 del yacimiento de Las Mayores (Numancia de la Sagra, Toledo): a) Foto del enterramiento durante la excavación. b) Urna funeraria antes de su excavación en el laboratorio. c) Detalle del enterramiento al interior de la urna; d) Esquema de los restos conservados; e) Recreación de la posición del individuo al interior de la urna; f) Planta y sección de la fosa. Figuras b-e elaboradas por L. Moreno Estefanel.

excavación constató una fase campaniforme y de la Edad del Bronce en el enclave. Se localizaron 605 fosas de las que se excava el 76,5\% (Perera et al. 2010). Veintiocho de ellas contienen restos funerarios de distinto tipo y conservación, de los que podemos avanzar la información de los realizados en urna, localizados en tres fosas del sector norte del yacimiento:

— LM245 (fig. 3): Fosa de boca circular y perfil en forma de saco rellena por una única matriz arcilloarenosa que colmató la estructura $29 \mathrm{~cm}$ antes de la colocación de la urna. La vasija se situó en posición horizontal con la boca hacia el oeste, aprovechando el rebaje de la pared sur de la estructura. Contenía el esqueleto completo de un neonato (?2 meses / 0,01 meses) con la cabeza orientada hacia la boca del recipiente. Puesto que se encontraba aún parcialmente adherido a las paredes de la vasija y así se depositó en el Museo (LM H245/9), pudimos excavarlo en el laboratorio. Esto nos permitió precisar su colocación, favorecida posiblemente por la flexibilidad de un bebé. Se colocó doblado sobre sí mismo, con una pierna sobre otra y los pies a la altura de la cabeza al igual que el brazo izquierdo, mientras el derecho permaneció extendido. Enviamos un fragmento de húmero para fechar por $\mathrm{C} 14$ con el siguiente re-

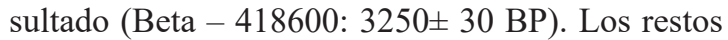
cerámicos y líticos aparecen repartidos por todo el relleno de la estructura, en capas previas e inferiores al enterramiento. Hay restos de talla en sílex y cuarcita, así como abundante cerámica sin remontaje alguno, toda ella lisa (65 fragmentos de paredes / 1210 gr), a excepción de un pequeño fragmento de campaniforme Ciempozuelos localizado en el sedimento previo a la urna. Se documentaron 30 restos de fauna de los que solo la mitad se pudo identificar como de Bos taurus adulto. Uno de ellos, un metacarpo, presentaba marcas de carroñeros que confirman su exposición previa.

— LM283 (fig. 4): Fosa de boca circular, perfil acampanado y relleno estratificado. Un primer relleno (UE3) arcilloso, con abundantes cenizas y carbones, ocupaba la parte central de la estructura hasta 

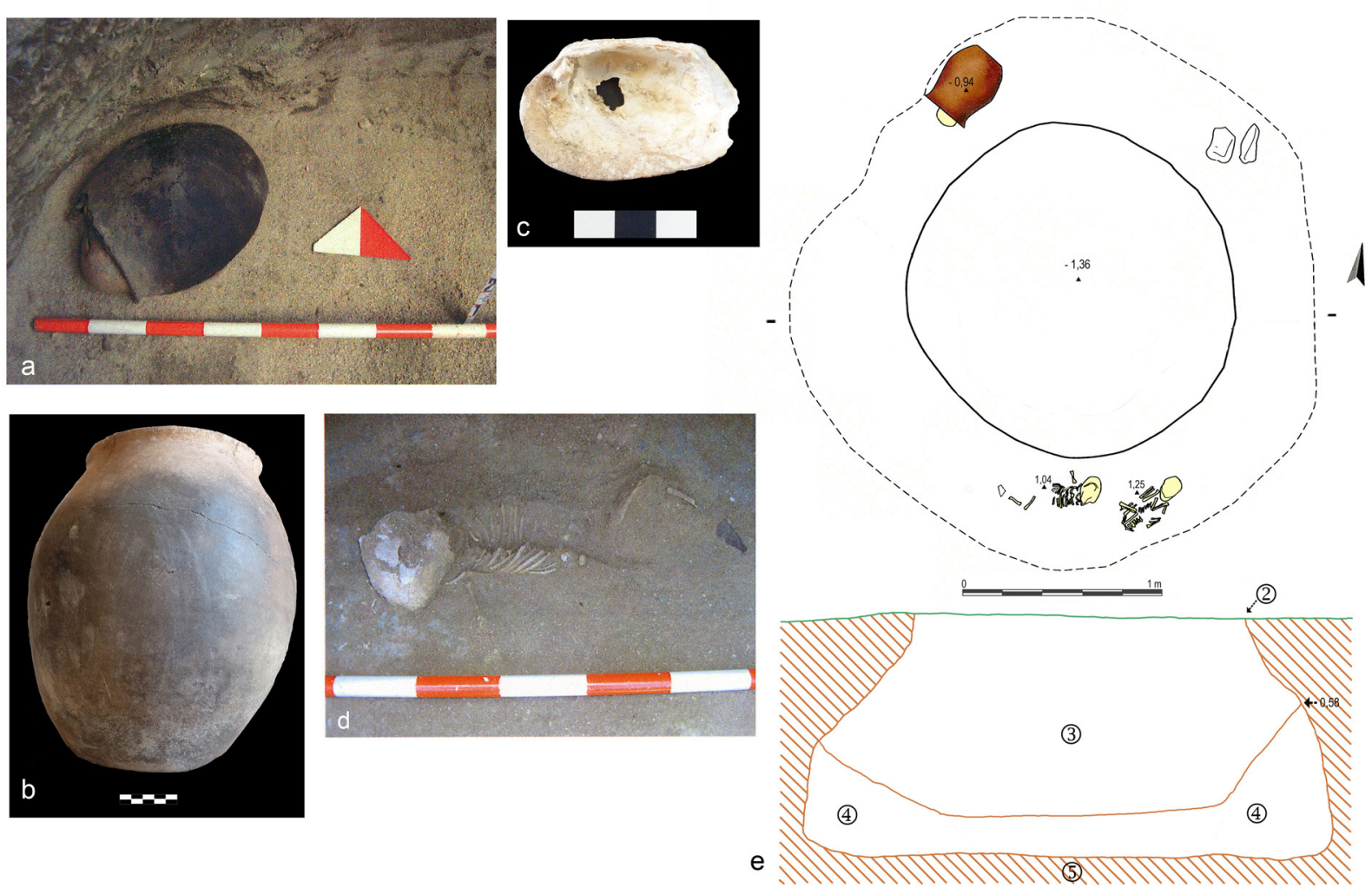

Figura 4. Fosa 283 del yacimiento de Las Mayores (Numancia de la Sagra, Toledo): a) Foto del enterramiento durante la excavación; b) Urna funeraria; c) Concha con perforación; d) Inhumación simple; e) Planta y sección de la fosa.

prácticamente la base. En él se encontraron restos dispersos y alterados de un individuo adulto masculino de 25-35 años (mandíbula sin tercer molar, fragmento de peroné izquierdo, un fragmento de vértebra cervical con signos artrósicos y costillas). Los análisis realizados sobre el fragmento de peroné determinaron una fecha C14 del $3300 \pm 30$ BP (Beta - 450104). Su presencia no se entiende como casual sino deliberada, pues todos los restos son compatibles y se insertan en una estructura utilizada como tumba antes. Así, el estrato inferior (UE4), formado por una matriz arcillosa libre de cenizas y carbones, contenía tres enterramientos desplazados hacia los laterales de la estructura. En el sector noroeste se colocó una vasija con un niño de 5 años \pm 16 meses, con una concha de río perforada (unio) (fig.4c). Su análisis permitió detectar cribra orbitalia bilateral de grado superior en el lado izquierdo, porosidad en pars basilaris y cribra en el cuello del fémur/húmero que podría ser propia del desarrollo. No se observa hipoplasia, pero sí defectos en el esmalte en los caninos inferiores. El cuerpo estaba muy contraído, con el cráneo sobresaliendo del recipiente en dirección suroeste. A partir de un fragmento de peroné obtuvimos una fecha C14 (Beta- 413610: 3340 \pm 30 BP).

En el lateral opuesto, al sureste, se localizaron dos inhumaciones infantiles simples tan próximas entre sí que su conservación articulada sugiere corto tiempo de deposición entre ambas. Primero se colocó a un niño en decúbito lateral derecho, muy flexionado, siguiendo un eje NE-SO y mirando hacia el centro de la estructura. Se trataba de un perinatal ( \pm 2 meses). Después se enterró junto a él a un niño de 6 meses ( \pm 3 meses) en decúbito lateral izquierdo, con piernas y brazos flexionados y siguiendo un eje E-O. En oposición al anterior su cráneo mira hacia el sur, hacia la pared de la estructura (fig. 4d). El estudio antropológico determinó signos que sugieren raquitismo. A partir de un fragmento de peroné obtu-

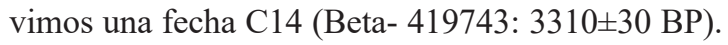
La cronología obtenida muestra escaso margen de tiempo entre los decesos, lo que descarta la identificación de los restos secundarios del individuo de 

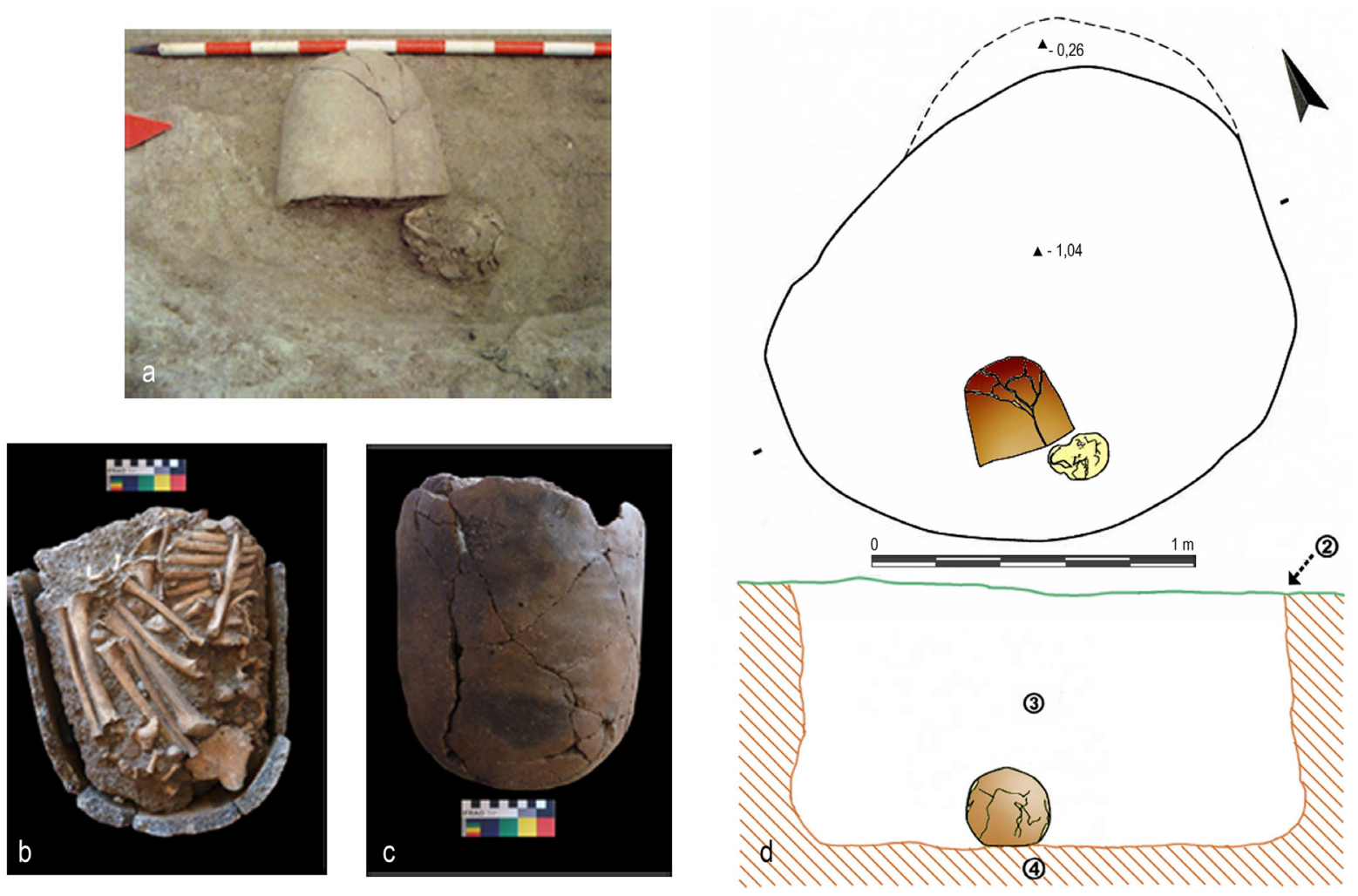

Figura 5. Fosa 405 del yacimiento de Las Mayores (Numancia de la Sagra, Toledo): a) Foto del enterramiento durante la excavación; b) Restos consolidados del enterramiento; c) urna funeraria; d) Planta y sección de la fosa.

mayor edad como un ancestro. Todo lo contrario, fechas y edades permiten pensar en una relación de parentesco entre los enterrados.

Los restos faunísticos encontrados en ambas UE son semejantes, con presencia de bovino, ovicaprino y suido de edades adultas. Sin embargo, los restos cerámicos difieren. Por un lado, en el estrato inferior que cubre los enterramientos infantiles se localizó un pequeño cuenco semiesférico completo que podría considerarse un ajuar colectivo, imposible de adscribir como tal a uno de los enterramientos. El resto de la cerámica (17 frags / 328 gr) era lisa salvo una única pared con un mamelón. La única forma era un pequeño borde exvasado y nada pudo ser remontado. Por su parte en la UE3 se encontraron 33 fragmentos (757 gr) entre los que había una pared con mamelón y dos más decoradas con un zigzag y espiguilla incisa característica del estilo Protocogotas.

— LM405 (fig. 5): Fosa de boca ligeramente oval y paredes rectas en cuya base plana, y próxima a la pared sur, se colocó una urna con un niño. Su estudio determinó una edad de 3 años ( \pm 12 meses) y rasgos masculinos en su mentón, aunque sea insuficiente para asegurar su sexo. La urna, un recipiente de tendencia cilíndrica, se localizó en posición horizontal con la boca orientada al sur. Contenía el esqueleto postcraneal hiperflexionado del individuo, mientras el cráneo se situaba fuera y en posición invertida, lo que implica su desarticulación antes de la colmatación de la fosa. Probablemente se protegió con algún elemento orgánico que permitió su desarticulación y desplazamiento en vacío. El esqueleto, en posición fetal, apareció fuertemente compactado con sedimento hasta el punto de ser consolidado con él (fig. 5b). Esta fuerte trabazón de los huesos, diferente del resto del sedimento de la estructura, también se observa en alguno de los enterramientos de La Loma del Lomo, mezclados con caliza (Valiente 1992: 74).

El relleno de la fosa, formado por una sola matriz arcillo-arenosa, contenía restos materiales escasos y poco diagnósticos, lo que hizo aún más imprescindible la obtención de una fecha a partir 
Tabla 1. Datos de los enterramientos en urna del Tajo asociados a los pithoi de la fig. 6.

\begin{tabular}{|c|c|c|c|c|c|c|c|c|c|c|c|c|c|c|}
\hline \multirow{2}{*}{\multicolumn{2}{|c|}{ Yacimiento }} & \multicolumn{2}{|c|}{ Estructura } & \multicolumn{3}{|c|}{$\begin{array}{c}\text { Tipo de } \\
\text { enterramiento }\end{array}$} & \multicolumn{4}{|c|}{ Datos del enterrado } & \multirow{3}{*}{$\begin{array}{l}\text { Ajuar / } \\
\text { ofrenda }\end{array}$} & \multirow[t]{3}{*}{ Fecha(BP) } & \multicolumn{2}{|c|}{$\begin{array}{c}\text { Caract. } \\
\text { patológicos }\end{array}$} \\
\hline & & \multirow{2}{*}{ Fosa } & \multirow{2}{*}{ Nicho } & \multirow{2}{*}{ Individual } & \multirow{2}{*}{$1^{\circ}$} & \multirow{2}{*}{$2^{\circ}$} & \multirow{2}{*}{$\mathrm{M}$} & \multirow{2}{*}{$\mathrm{F}$} & \multirow{2}{*}{ Indet. } & \multirow{2}{*}{$\frac{\text { Edad }}{19-24 \text { años }}$} & & & oral & F. Porosos \\
\hline ES & 101B & & & & & & & & & & & & & \\
\hline LL9 & $11 \mathrm{D}-1$ & & & & & & & & & 2-3 años & $\begin{array}{l}\text { punzón? / } \\
\text { Sus scrofa }\end{array}$ & & & \\
\hline LL10 & $11 \mathrm{C}-1$ & & & & & & & & & 5-6 años & $\begin{array}{c}\text { concha / Sus } \\
\text { scrofa y Canis } \\
\text { familiaris } \\
\end{array}$ & & & \\
\hline LL12 & $12 \mathrm{C}-1$ & & & & & & & & & 2-3 años & $\begin{array}{l}\text { ápice de pun- } \\
\text { zón de hueso }\end{array}$ & & & \\
\hline LL13 & $12 \mathrm{C}-4$ & & & & & & & & & $\begin{array}{c}\text { 30/40-45 } \\
\text { años }\end{array}$ & $\begin{array}{c}\text { punzón hueso / } \\
\text { colgante en } \\
\text { molar bóvido } \\
\end{array}$ & $3340 \pm 100$ & & \\
\hline LL15 & $13 \mathrm{C}-1$ & & & & & & & & & $0-3$ meses & & & & \\
\hline LL21 & 10B-2 & & & & & & & & & 6-7 años & & & & \\
\hline LL23 & $12 \mathrm{~F}-1$ & & & & & & & & & 2 años & & & & \\
\hline LL24 & $12 \mathrm{~F}-3$ & & & & & & & & & $2-2,5$ años & & & & \\
\hline $\mathrm{LM}$ & 245 & & & & & & & & & \pm 2 meses & & $3250 \pm 30$ & & \\
\hline LM & 405 & & & & & & & & & 3 ( \pm 1 años) & & $3260 \pm 30$ & & \\
\hline LM & 283 & & & & & & & & & $5( \pm 1,5$ años $)$ & concha & $3340 \pm 30$ & & \\
\hline $\mathrm{HU}$ & & & & & & & & & & infantil & & & & \\
\hline VI & E-145 & & & & & & & & & $<6$ meses & & & & \\
\hline
\end{tabular}

Abreviaturas: ES: El Espinillo (Baquedano et al. 2000); LL: La Loma del Lomo (Valiente 1992); LM: Las Mayores (inéditos);
HU: Arroyo de Humanejos-Km.24, N-401 (Vega et al. 2014); VI: Ventaquemada I (Pérez Villa 2015).

M (masculino), F (femenino), Fr. (fragmento) de un fragmento de clavícula del enterrado (Beta413611: $3260 \pm 30$ BP). Toda la cerámica es lisa (34 fragmentos /666 gr) y no hay industria lítica. Los restos faunísticos identificables ( 5 fragmentos) indican la presencia de Bos taurus y Canis familiaris.

\section{CARACTERIZACIÓN DE LOS ENTERRAMIENTOS EN URNA DEL TAJO}

Valorando en conjunto la documentación reunida y en especial los contextos más claros (tabla 1), hay ejemplos de pithoi en las tres provincias analizadas pero su distribución es un tanto desigual, sin que podamos aún esclarecer la causa. En Guadalajara, con un único yacimiento pero el más representativo cuantitativamente, su vacío oriental puede atribuirse a la falta de excavaciones de la Edad del Bronce, sin embargo en Madrid, el área sur que reúne numerosos contextos funerarios de esta etapa presenta un número muy reducido de enterramientos en urna.

Todos los yacimientos pertenecen al tipo de poblamiento característico de la Edad del Bronce en la zona. Son poblados abiertos, sin delimitación artificial alguna, que o bien se ubican en áreas de altura, como es el caso de La Loma del Lomo, o en terrazas y zonas bajas como ocurre en Las Mayores. No conocemos hasta el momento ningún enterramiento en cueva como se documentó en la próxima provincia de Cuenca (Martínez Navarrete 1988: 2225 y 2226).

Se trata de campos de hoyos, yacimientos formados por estructuras subterráneas entre las que raramente identificamos viviendas de la Edad del Bronce (Barroso 2016). Lo más frecuente es que las fosas sean mayoritarias o incluso las únicas estructuras documentadas, prestándose a diferentes usos primarios y amortizaciones finales, entre ellos el servir de tumbas. Determinar la sincronía de todas las estructuras no es fácil, pero todo indica 
que los asentamientos tienen una larga duración, como poco desde el Calcolítico, con establecimientos continuos o reiterados del mismo espacio hasta mediados o finales del II milenio a.C. Hay, por tanto, un evidente vínculo con la tierra del que los muertos son testigos directos.

La integración de los muertos en ese mismo espacio doméstico es clara, asociándose a las áreas de producción y reproducción del ciclo agrario (Díaz del Río et al. 1997), sin embargo seguimos sin poder profundizar más. Es poco lo investigado sobre la disposición interna de los poblados y con ello de la situación que ocupan los enterramientos (Barroso et al. 2014). Se diferencian agrupaciones de estructuras de uso contemporáneo o sectores de actividad entre los que no faltan los funerarios, como mencionamos en La Loma del Lomo. Este yacimiento, uno de los pocos excavados prácticamente por completo (Valiente 1995: 140), nos permite también valorar el tamaño de las agrupaciones funerarias de la Edad del Bronce. En sus $1.637 \mathrm{~m}^{2}$, con 114 fosas de la Edad del Bronce, se localizaron 23 enterramientos de los que un $34 \%$ son en urna, aun cuando la población infantil enterrada es del $65 \%$. Los datos difieren bastante del resto de yacimientos donde no conocemos extensiones bien delimitadas. En Las Mayores, 453 estructuras se asignan a la Edad del Bronce (Perera et al. 2010) y solo tres de sus enterramientos han sido en urna, lo que supone una proporción en la misma línea de la observada en Arroyo de Humanejos-Km 24 o Ventaquemada I, en el entorno del $10 \%$ (tabla 2).
Con la excepción mencionada de Cerro del Obispo, todos los enterramientos en urna del Tajo se localizan en última instancia en fosas, junto a otras tantas inhumaciones simples. Se elige uno u otro tipo de acondicionamiento final del inhumado e incluso, como en LM283, conviven en una misma estructura, pero en cualquiera de ellos el esfuerzo no es significativo. La mayor parte de las fosas parecen haber sido abiertas para otros usos y reutilizadas como tumbas (Pérez Villa 2015: 112) por mucho que encontremos urnas situadas en la base de la estructura o a media altura, sobre niveles previos de sedimento.

La única preparación estructural serían los nichos abiertos en la pared de las fosas. En ellos se colocan algunas urnas, mientras otras se disponen directamente en las fosas, ocupando posiciones laterales junto a sus paredes. Pocas se colocaron en vertical, de pie o invertidas, y muchas más en horizontal, siendo esta posición la más apropiada en los nichos por evidente cuestión de espacio. Se colocan exentas o, como es preferente en La Loma del Lomo, encajadas en restos de pavimentos, calzadas o rodeadas por piedras un tanto irregulares, semejantes a las que cierran los nichos. Todas aparecen fragmentadas por la presión que tuvieron que soportar, pero presumiblemente fueron depositadas enteras. La única excepción es un enterramiento en nicho de La Loma del Lomo (12F-3) en el que la vasija se rompe intencionadamente. Sus dos mitades se superponen para cubrir el cuerpo y adaptarse a la forma de la oquedad

Tabla 2. Yacimientos del Tajo, La Mancha y argáricos con número de inhumaciones o tumbas y el porcentaje de ellas que corresponde a las urnas de la Edad del Bronce.

\begin{tabular}{|l|c|c|l|}
\hline \multicolumn{1}{|c|}{ Yacimientos } & $\mathrm{n}^{\mathrm{o}}$ inhumados & en vasija & \multicolumn{1}{c|}{ Bibliografía } \\
\hline La Loma del Lomo & 23 & $34 \%$ & Valiente 1992 \\
\hline Las Mayores & $24 ?$ & $12 \%$ & Perea et al. 2010 \\
\hline Humanejos & 10 & $10 \%$ & Vega et al. 2014 \\
\hline Ventaquemada 1 & 13 & $7 \%$ & Pérez Villa 2015 \\
\hline \multicolumn{1}{|c|}{ Yacimientos } & $\mathrm{n}^{\text {o }}$ sepulturas & en vasija & \multicolumn{1}{c|}{ Bibliografía } \\
\hline La Motilla de Azuer & $62^{*}$ & $8 \%$ & Nájera et al. 2010 \\
\hline El Argar & $227^{*}$ & $85 \%$ & Lull et al. 2004 \\
\hline La Bastida de Totana & $73^{*}$ & $80 \%$ & Lull et al. 2011 \\
\hline Fuente Álamo & $107^{*}$ & $59 \%$ & Kunter 2000 \\
\hline Peñalosa & $17^{*}$ & $17 \%$ & Contreras et al. 2000 \\
\hline
\end{tabular}

(*) Los datos no son totales sino que corresponden a la muestra recogida en la referencia bibliográfica especificada. 
que además se cierra con piedras (Valiente 1992: 159). Esta idea de protección y cierre también se percibe en las tapas de algunas vasijas mediante piedras o cazuelas invertidas y posiblemente, otros elementos orgánicos que justifiquen desplazamientos como el mencionado en LM405.

Todos los enterramientos son individuales y en principio, con las dudas ya expuestas, primarios. La posición de los cuerpos, donde se ha podido conocer, es encogida, con brazos y piernas flexionados adoptando una posición fetal lateral. Ciertamente las posiciones flexionadas son las habituales en los enterramientos prehistóricos, no solo en la Edad del Bronce (Pérez Villa 2015: 122), pero aquí vienen determinadas por el propio contenedor cerámico. Los ejemplos de Las Mayores son claros al respecto. Los dos neonatos en inhumación simple del enterramiento LM283 también adoptan posturas flexionadas similares a las del tercer enterramiento depositado en urna junto a ellos. Por otro lado la reconstrucción de la postura del enterramiento LM245 muestra un neonato con el cuerpo realmente replegado (fig 3e), que ocupaba la urna de menor tamaño documentada, de poco más de 6 litros. La cabeza suele orientarse hacia la boca del recipiente e incluso sobresale en Ventaquemada I o Las Mayores 283 y 405.

Desde un punto de vista morfológico, con 14 ejemplares de urnas (fig. 6), únicamente cabe realizar una descripción sencilla que nos permita valoraciones generales. Encontramos formas simples y carenadas con bordes exvasados, a excepción de la urna de paredes y borde recto de LM405. Las simples responden a formas globulares, ovoides, que son las mayoritarias, además del mencionado recipiente cilíndrico. Las formas compuestas son fuentes abiertas con carenas en el tercio inferior, que también se usan como tapa en uno de los enterramientos de La Loma del Lomo (Valiente 1992: fig. 57). A su vez cada grupo incluye gran variedad de tamaños, así como piezas lisas o decoradas. Verdaderos pithoi, en cuanto grandes recipientes, los encontramos en La Loma del Lomo, destacando los ejemplares ovoides (p. ej. la urna de 12C-4 con 851 de capacidad). Su gran desarrollo en altura contrasta con su pequeña base dándoles cierta inestabilidad.

Las decoraciones son frecuentes. Once de ellas presentan algún motivo plástico, mamelones o cordones con ungulaciones que en ocasiones también aparecen decorando los labios. Esta decoración no va acompañada de una gran calidad del tratamiento de las superficies, en especial en los contenedores de mayor tamaño, meramente alisados e incluso con cocción deficiente (Valiente 1992: 56). No ocurre los mismo en las formas carenadas que tienen espatulados finos. Es difícil determinar si la función primaria de esta cerámica fue la funeraria, pero al menos en La Loma del Lomo, donde hay un exhaustivo conocimiento de los materiales del poblado, ninguno de los recipientes responde a formas exclusivas de este uso (Valiente 2001:179).

La preferente asociación de contenedor funerario a individuos infantiles es palpable en el Tajo igual que en otros círculos peninsulares, aunque también hay enterramientos de adultos. El más claro, el adulto localizado en Loma del Lomo (12C-4) cuya estatura estimada de $1,62-1,64 \mathrm{~m}$ es muy próxima a la media de los individuos masculinos de la Edad Bronce en la zona (Pérez Villa 2015: 79). Respecto a los niños, la muestra incluye perinatales e infantiles de hasta 7 años, es decir, individuos aún muy ligados al núcleo familiar. No puede determinarse claramente una relación exclusiva entre un tipo de urna y edad, si bien el tamaño necesario según los cuerpos a contener fue un condicionante evidente (por ejemplo, las cazuelas contienen individuos de no más de 3 años). De esta forma, el menor tamaño de los individuos infantiles y su fácil introducción puede ser un elemento a tener en cuenta en la elección de este tipo de enterramiento (Pérez Villa 2015: 121), igual que la preservación del cuerpo dada la baja mineralización ósea de los niños o la garantía de no perder la unidad de los pequeños restos en el caso de desplazamiento y reutilización de la tumba. Sin embargo, nada de esto explica que algunos individuos perinatales $u$ otros infantiles de la misma edad queden fuera de esta práctica en los mismos yacimientos, incluso utilizándose la misma fosa como en LM283. En este último caso solo la edad de $5 / 6$ años, frente a los otros dos niños que no alcanzan el año, podría ser el motivo de recibir urna.

Los ajuares asociados a los enterramientos en urna siguen la misma pauta austera del resto de los enterramientos de la Edad del Bronce en el Tajo, aun cubriendo todos los grupos de edad (Pérez Villa 2015; Barroso 2016). En conjunto, de los 14, solo 5 tienen algún elemento sin que se observen en ello diferencias por edad o sexo. Quizás el dato cualitativo es más indicativo, pues los ítems corresponden a pequeños adornos en forma de colgantes, punzones de hueso, una única pieza de metal sin relación clara con el enterramiento (Valiente 1992:112) y el cuenco cerámico de la tumba LM283. Salvo uno de los colgantes sobre concha marina, tampoco la materia prima sobre la que se realizan revaloriza las dádivas. En esta ocasión, como en el resto de los adornos, cabe reflexionar sobre si son un reconocimiento social tras su muerte o suponen llevarse a la tumba efectos que ya portaban en vida. En La 

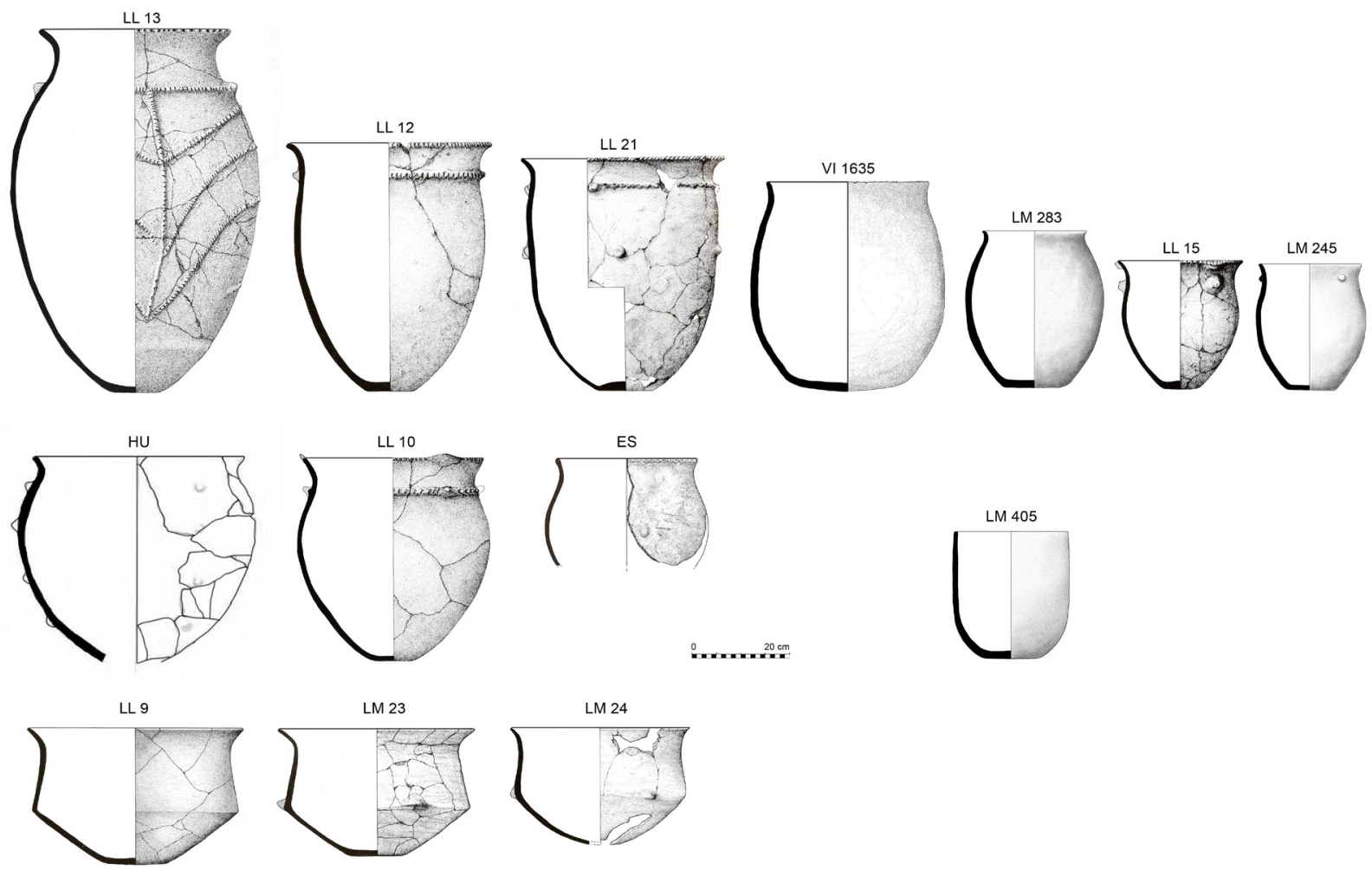

Figura 6. Pithoi del Tajo interior: LL (La Loma del Lomo, a partir de Valiente 1992: figs. 37, 57, 67, 75, 82, 98 y 150); LM (Las Mayores); VI (Ventaquemada I, 2005/43/ 1635); HU (Arroyo de Humanejos-Km. 24, N-401, a partir de Vega et al. 2014 : fig. 4); ES (El Espinillo, a partir de Baquedano et al. 2000: fig. 10).

Loma del Lomo encontramos, además, ofrendas cárnicas identificadas con restos parciales o completos de cerdo, perro y vaca.

Contamos con cuatro fechas (tabla 1). La obtenida en La Loma del Lomo tiene una alta desviación. Procede del fondo $12 \mathrm{C}-4$, de huesos presumiblemente de fauna tomados al mismo nivel del enterramiento I-14,891: $3340 \pm 100$ a.C. (Valiente 1992: 195). Las otras tres proceden del yacimiento de Las Mayores y nos sitúan en un margen entre 1690-1450 cal BC., en lo que convencionalmente se identifica como Bronce Medio, a la par que otras tantas inhumaciones simples en fosa. Determinar si este es también su momento de implantación o si tiene ahora su mayor auge, exigiría de más muestras y fechas.

\section{DISCUSION: CONTACTOS, INFLUENCIAS Y ASOCIACIONES}

Es recurrente hablar del Argar al tratar los enterramientos en vasijas de la Edad del Bronce peninsular porque es allí donde tienen mayor profusión, pero no es la única área de referencia. Conviene no olvidar que se trata de una forma de enterramiento presente en todo el Mediterráneo. Los enterramientos en vasijas, dentro o entre las viviendas, se conocen desde comienzos del Neolítico en el sureste de Europa, prevaleciendo la idea de su legado desde Próximo Oriente como un elemento más del proceso de neolitización del continente (Bacvarov 2008: 66). Se asocian mayoritariamente a enterramientos infantiles, mostrando un amplio registro geográfico y temporal que incluye tierras búlgaras, griegas o del Mediterráneo central y una extensión temporal hasta la Edad del Hierro. Durante este largo periodo de tiempo las variantes serán muchas y similares a las peninsulares. Se incluyen los adultos en grandes pithoi, hay cierres diversos de las vasijas, incluso mediante otro recipiente, fragmentos cerámicos o losas, y no faltan las huellas de reparación, reciclado y uso previo que garantizan la procedencia doméstica de los contenedores. Cambian también las colocaciones de la urna y del individuo en el interior (Whittaker 2014; Orrelle 2008).

Volviendo al Argar, su amplio registro funerario es uno de los principales baluartes de la interpretación de 
su sociedad como estratificada. El ritual funerario argárico se define como normalizado y con claras muestras de distancia social entre los enterrados. Sin embargo, la elección de uno u otro tipo de enterramiento queda fuera de la uniformidad. El uso de covachas, cistas, fosas o urnas no implica posición social alguna del individuo, sino que responde a tradiciones locales y en el caso de las urnas a "una solución original argárica" (Lull y Estevez 1986: 445), que además es la predilecta para los enterramientos infantiles. En el propio yacimiento de El Argar, nueve de cada diez enterramientos infantiles se realizan en urna. De hecho, no la aparición pero sí la generalización de las urnas desde comienzos del II milenio a.C. (1940 cal BC) se relaciona con el momento de incorporación de los niños fallecidos a los contextos de habitación (Lull et al. 2004: 249). Ciertamente es lógico pensar que los niños son los más fáciles de introducir en una vasija, pero no todo se reduce a criterios funcionales, porque también hay adultos enterrados en ellas y preferencias regionales. Las urnas son más frecuentes en las tierras orientales del sureste peninsular, donde también encontramos variedades propias como los cenotafios o las urnas dobles halladas en el Guadalentín (Aranda et al. 2015: 120), afrontadas como en Lorca (Martínez et al. 1996) o la Bastida de Totana (Lull et al. 2011: 64).

Algo parecido pasa con la elección de los contenedores cerámicos. Se observan preferencias por algunas formas cerámicas y una relación entre forma y edad del fallecido que se interpreta dentro de la normalización del ritual funerario argárico. Sin embargo, hay a la vez aspectos eminentemente funcionales, como la necesidad de mayor capacidad de recipiente para los individuos de mayor edad, que hace que algunas formas se conviertan en las mayoritarias (Lull et al. 2004: 252-253). En relación con su manufactura hay pithoi de gran tamaño cuya elaboración exigiría elevados niveles de destreza y especialización (Lull et al. 2015: 108-109) y otros tantos que habría que situar dentro de una producción doméstica, familiar y fuera de los usos normalizados (Aranda 2010: 90). Análisis morfológicos y tecnológicos de las urnas funerarias infantiles de varios yacimientos, entre ellos Gatas, muestran en su elaboración anomalías impropias de un artesanado especializado, siendo más atribuibles a una manufactura inexperta (Colomer 2005). Parece ser, por tanto, que excepción y norma rigen los enterramientos en urna argáricos, con variantes según se trate de adultos o infantiles. Ahora bien, el rasgo distintivo del Argar está sin duda en el ajuar que, en las urnas, como en el resto de los enterramientos argáricos, muestra notables contrastes. No hay más que fijarse en la urna de la tumba "principesca" de La Almoloya que reúne dos enterramientos adultos y uno de los ajuares más ostentosos del Argar (Lull et al. 2015). En el caso de los enterramientos infantiles, los ajuares están formados mayoritariamente por cerámica, elementos metálicos y adornos que se incrementan con la edad. De esta forma, perinatales y neonatos raramente tienen ajuar, mientras que los 6 años se confirman como edad de inflexión en la capacidad de adquirir bienes. Todo ello implica un acceso diferencial a la riqueza y una posición social heredada (Lull et al. 2004). Completando el ritual funerario encontramos también ofrendas de porciones cárnicas interpretadas como parte de los banquetes funerarios. Hay una preferencia por bovinos y ovicaprinos jóvenes que se depositan siguiendo un patrón determinado por la edad y posición social del inhumado (Aranda y Esquivel 2007).

El protagonismo de los pithoi entre la población infantil de La Mancha también es reseñable. Los hay tanto en fortificaciones en altura, caso de La Encantada, monumentos como El Castillejo del Bonete o en las motillas (Gusi y Luján 2011). La motilla en la que más se ha trabajado hasta el momento, Azuer (Nájera et al. 2010a), ha proporcionado cinco enterramientos en vasijas pertenecientes a la fase III y IV (1800-1400/1350 a.C.). En el conjunto de los enterramientos infantiles destaca la sencillez y escasa ostentación de los ajuares presentes solo en un $19 \%$ de las tumbas.

En el Tajo, los enterramientos en vasijas junto a piezas particulares como la espada del Arenero de la Perla sirvieron para diferenciar una cultura argárica en la capital (Pérez de Barradas 1936: 73), en un momento en el que el círculo cultural argárico se equiparaba con la península. Restringida su extensión al sureste, enterramientos en vasija como los de Euskalduna, junto con un fragmento de copa, se entienden como la llegada de tradiciones argáricas a tierras del Manzanares (Almagro 1960: 28) o la argarización de grupos autóctonos que ahora realizan inhumaciones bajo el suelo de las viviendas o en sus proximidades (Valiente 1991: 144; 1992:232). El referente argárico sigue presente en el análisis del registro de los enterramientos en urna (Martínez Navarrete 1988: 1031; Blasco 1997: 188; Aliaga 2012: 391-392; Vega et al. 2014:387) y es comprensible porque es allí donde tienen mayor arraigo.

Por otro lado, tenemos constancia de elementos materiales propios de Cogotas, cerámica con sus típicas decoraciones, reproducidos en territorios distantes y socialmente diferentes donde también se realizan enterramientos en urnas. Un buen ejemplo es el poblado 
argárico de Peñalosa, donde la incorporación de cerámicas con formas y decoraciones Cogotas a la vajilla propia del yacimiento ha servido para argumentar contactos, intercambios e influencias entre comunidades meseteñas y del Alto Guadalquivir en el momento final de la secuencia argárica, no después del 1500 a.C. (Contreras y Alarcón 2012). Otro más es el yacimiento levantino de Cabezo Redondo, esta vez en la periferia argárica, en cuyo registro funerario no faltan los enterramientos infantiles en urna. Las cerámicas características de Cogotas o sus imitaciones aparecen en varios de sus departamentos caracterizando el Bronce Tardío de la zona. La fuerte posición del enclave entre el $1600-1300$ cal BC debe entenderse dentro de las trasformaciones sociales y políticas que conllevan los momentos finales del Argar y la estratégica posición conectando Meseta, Sur y la Alta Andalucía (Hernández 2009 y 2012).

Evidentemente recurrir al legado argárico en el Tajo no es imprescindible, pues los enterramientos en vasija superan el Sureste, siendo una seña característica del Bronce mediterráneo peninsular. Admitir influjos o comportamientos influenciados desde otros círculos culturales tampoco tiene más inconveniente. Ahora bien, eso no implica supeditar la formación de las comunidades del Bronce interior a agentes externos. Las fechas de los enterramientos en urna conocidas hasta el momento sugieren su inserción en comunidades de la Edad del Bronce ya formadas, coincidiendo con un momento avanzado también de la cultura de las Motillas y El Argar. En el Tajo, los enterramientos en urna no implican una producción cerámica especial, ni mucho menos especializada, ni suponen una consideración particular, que sepamos, para el individuo al que se asocian. No son numerosos ni se presentan por igual en sus agrupaciones de la Edad del Bronce. No conllevan, tampoco, rasgos verdaderamente distintivos del Argar. La individualidad de los enterramientos, la construcción de covachas, las alabardas o las copas cerámicas, en su momento consideradas imperativos argáricos al interior, tienen hoy claros precedentes asociados a comunidades de tradición calcolítica en la zona (Bueno et al. 2008; Blasco et al. 2016; Flores y Garrido 2016).

Más interesante que los influjos, desde el punto de vista del Tajo, es observar las comunidades del II milenio a.C. que hay detrás de este tipo de enterramiento, repasando los datos materiales, estratigráficos y cronológicos de los que disponemos asociados a ellos.

Los enterramientos en urna no se asocian a Campaniforme ni a los elementos que forman sus ajuares característicos, por mucho que en el Tajo los tipos
Ciempozuelos (Ríos et al. 2012: Bueno et al. 2008) alcancen el primer tercio del II milenio a.C. El fragmento Ciempozuelos localizado en el relleno de LM245, comprensible dentro de la compleja dinámica de uso de los campos de hoyos, es insuficiente para mantener dicha asociación.

Se observa también una clara disociación entre el uso de pithoi funerarios y la alfarería decorada Protocogotas. Prueba de ello son las características de las vasijas de enterramiento ya descritas o del único elemento cerámico de los ajuares, el cuenco liso de LM283. Tampoco debe dejarse de lado que los materiales cerámicos incluidos de forma deliberada o accidental en las tumbas son fragmentos lisos, por mucho que subordinar depósitos funerarios primarios a materiales secundarios originados en actividades bien distintas, no sea del todo procedente. Por último, resulta categórico que no conozcamos un claro enterramiento con Cogotas, en la Meseta Norte o Sur (Esparza et al. 2012; Barroso et al. 2014), ligado a esta práctica de las urnas.

Tenemos, además, un registro estratigráfico en esa misma tumba de Las Mayores (LM283) cuyos enterramientos infantiles, uno de ellos en urna, ocupan una posición inferior dentro de la estructura. La tumba seguirá activa, de forma que el estrato superior incluye los restos secundarios de un adulto que expresamente quiso ligarse a los niños, pues los rellenos estratificados no son frecuentes en el yacimiento. Su fecha sitúa su muerte muy próxima a las de los infantiles pero su desarticulación debió de producirse en un contexto diferente. Evidentemente solo tenemos una superposición espacial de registros materiales, cerámicas lisas y decoradas Protocogotas, que no tiene por qué implicar una gran separación temporal. Es más, no deja de ser una pequeña representación significativa $(6 \%$ de la cerámica contenida en la UE) acompañada de material genérico indiferenciable del localizado en el estrato inferior. De estos datos pueden sugerirse varias lecturas: o bien se ha producido un descarte intencionado de la cerámica decorada Cogotas acompañando a los enterramientos inferiores o esta no se elaboraba aún en ese momento, siendo enterramientos previos, o bien la cerámica que forma parte del relleno en cada UE sucesiva, lisa y decorada, procede de contextos de uso y consumo diferentes que justifiquen su ornamentación.

Desde el punto de vista de la cronología absoluta los márgenes del C14 permiten poca precisión. Las fechas obtenidas aseguran que los enterramientos en urna se están realizando como poco desde comienzos del siglo XVII a.C., por lo que no deben ser ajenos a las comunidades Cogotas I cuya primera etapa, Protocogotas, en 
la Meseta trascurre del 1800-1450 a.C. (Esparza et al. 2012: 268; Blasco 2012: 191). Es más, ambos, fórmula funeraria y cerámicas decoradas, se presentan agregados espacialmente en poblados como Las Mayores, donde a escasos metros de las tumbas con pithos encontramos tumbas con enterramientos simples, fechas sincrónicas y fragmentos con decoraciones de espiguillas transferidas a los rellenos de las tumbas desde sus contextos de procedencia y en una escasa proporción (3-4 \%) del total de la cerámica. La propia tumba LM283 reúne posiblemente un grupo familiar enterrado en momentos de distinta selección o tradición cerámica. Difícil interpretar que sus poblaciones vivas, utilizando un mismo espacio doméstico en el que enterrar a sus muertos, se sintieran "distintas", pero ciertamente desde el punto de vista arqueológico las etiquetamos como tales porque conllevan una cerámica diferente como sello de identidad. Es decir, se percibe una convivencia, vecindad y avenencia social en cuanto agrupación y una diferencia en el producto social que supone en este caso la cerámica que se hace y usa.

\section{CONCLUSIONES}

Los enterramientos en urna son una práctica funeraria utilizada por las comunidades de la Edad del Bronce del interior de forma desigual pero en todo caso minoritaria. En pocos yacimientos el área excavada se aproxima a la extensión completa del enclave, pero dentro de esta parcialidad, solo en La Loma del Lomo, con un tercio de la población enterrada, alcanzan un sensible porcentaje. Tampoco su localización en las tres provincias por las que discurre el Tajo denota sectores o regiones de mayor relevancia, dado lo excavado en cada una de ellas. En todo caso, lo contario, "vacíos" significativos como el entorno de la capital madrileña, en donde las múltiples intervenciones de los últimos años en numerosos contextos funerarios de la Edad del Bronce no implican muchos más enterramientos en urna. De esta forma, en el yacimiento que a día de hoy presenta mayor número de enterramientos de esta etapa, Los Berrocales (Aliaga y Megías 2011), con más de medio centenar y en cronologías parejas a las obtenidas en Las Mayores, ninguno ha sido realizado en urna.

Sin embargo, este carácter minoritario no los deja al margen de los aspectos que caracterizan el conjunto de enterramientos de la Edad del Bronce en la zona. Por un lado, conectan con la tradición funeraria característica pues las urnas se sitúan en nichos y fosas previamente excavadas para otros fines. No hay en ello un profundo cambio ideológico más allá de recoger directamente el cuerpo en un contenedor cerámico. Tampoco son distintos los ajuares y ofrendas animales, que en más de la mitad de ellos están ausentes y son tan sencillos que desvirtúan cualquier consideración de distancia social. Por otro, apoyan la evidente asociación entre espacio funerario y doméstico. De hecho la incorporación de urnas cerámicas al ámbito funerario desde el doméstico, siendo incluso reutilizadas, es prueba de una manifiesta indiferencia por separar ambos ámbitos (Bruck 1999: 63).

A pesar de su corto número observamos numerosas variantes en la deposición final. Cambia la colocación de la urna, mayoritariamente horizontal pero no la única, su cierre y la colocación invertida o no del individuo, todo lo cual plantea una enorme versatilidad que aumenta cuando introducimos otras variables como los diferentes tipos de urnas, las edades de los enterrados y ajuares, dando idea de ser aspectos sin fórmula alguna, decididos en el momento del entierro. Se perciben, por tanto, comportamientos de ámbito reducido, familiar, que son los propios de los contextos funerarios de la Edad del Bronce frente a la visibilidad colectiva de momentos anteriores.

Las urnas repiten tres morfologías básicas y sus decoraciones plásticas o impresas no parecen suponer valor añadido. Decoradas o no, son el elemento común del enterramiento en cuestión, de ahí que la historia del recipiente, su elaboración, propiedad y su uso sean aspectos relevantes que se involucran junto al inhumado, aportándole un pasado que en el caso de los niños de corta edad ni siquiera han tenido.

Mayoritariamente se asocian a enterramientos infantiles y el tamaño del recipiente pudo actuar como condicionante al respecto. Sin embargo, no todos los niños se entierran en urnas sin que podamos determinar el motivo de la selección. Las patologías que han dejado huella no establecen diferencia alguna con el resto de la población. Son inexpresivas, por lo que debemos pensar en causas naturales ligadas a la elevada mortalidad infantil de las poblaciones del pasado (González Martín 2008). Por otro lado, que los enterrados en urnas sean solo unos pocos no es suficiente para ver en ello una mayor consideración social y conviene recordar que ni siquiera en una sociedad jerarquizada como El Argar el tipo de enterramiento depende del estatus social del individuo. En LM283 planteamos que la edad fuera la consideración del agraciado con urna, pero esta distinción sólo se comprende dentro de su grupo familiar, no como una normativa extensible a toda la comunidad. Tampoco podemos olvidar el valor simbólico de la práctica desde el momento que en La Loma del 
Lomo se asocia por igual a restos humanos que a ofrendas animales (Valiente 1992: 130) o implica la elección de pithoi con cuellos estrechos que sin duda dificultarían la introducción del cuerpo. Al respecto, en la posición contraída de los cuerpos, así como en la posición de la cabeza cercana a la boca del contenedor se ha visto un renacer, una analogía entre recipientes y útero materno (Orrelle 2008: 73; Mc George 2012). Esta relación madre-hijo y la inclusión de perinatales que han desarrollado únicamente vínculo social con la progenitora son aspectos a tener en cuenta junto a la producción y trasmisión de la cerámica, en la que el papel de la mujeres, sin ser único, debió ser relevante (Abarquero 2012: 95-96).

Las urnas funerarias carecen de tradición anterior a la Edad del Bronce, no solo en la Meseta sino en el resto de la Península. Es en El Argar donde tienen mayor aceptación y las fechas más antiguas, desde comienzos del II milenio a.C. (Lull et al. 2004), de ahí su incentivo para explicar cualquier hallazgo fuera del Sureste. Sin embargo, en el Tajo interior, los contactos e influencias no solo con el Argar sino con todo el Sur peninsular existieron durante la Edad del Bronce, de forma que, más que focalizar la cuestión, hay que destacar la apertura del área a prácticas funerarias presentes en toda la fachada meridional mediterránea, casi a la par que se produce una amplia dispersión de elementos propios de la Meseta, cerámicas Cogotas (Abarquero 2012).

En ningún caso puede hablarse de cambios en profundidad de los contextos locales. Los enterramientos en urna, por sí solos, son insuficientes para plantear una "argarización" del área interior. Faltan los elementos realmente distintivos de El Argar, sus modelos de habitación característicos y los ajuares funerarios reveladores de claras disimetrías sociales, mientras que las producciones cerámicas carenadas o los enterramientos en urnas convergen en más áreas peninsulares que el Sureste. El propio concepto funerario de la "individualidad" que predica El Argar se verá alterado en el Tajo. Las limitaciones de espacio que implica toda urna se suplen con la mayor capacidad de las fosas que pueden reunir varios decesos, incluso de individuos ya desarticulados.

Con las fechas que tenemos hasta el momento, los enterramientos en urna del Tajo se sitúan a comienzos del Bronce Medio y perduran poco tiempo, hasta mediados del siglo XV a.C., manteniéndose dentro de una tradición alfarera de piezas lisas o decoraciones impresas y plásticas diferentes de los motivos profusos que caracterizan las cerámicas campaniformes o Cogotas. Esto encaja con la propuesta de partida que los sitúa al margen de las comunidades ligadas a las cerámicas Cogotas (Blasco 1997: 187) y con ello en una cronología post quem para esta alfarería en la zona. El indicador nuevamente es un tipo cerámico, pero ello no implica rupturas ni cambios. Lo que realmente tenemos son evidencias de una asociación temporal y espacial, quizás familiar, que sugiere la existencia de una dinámica social continua que relativiza la diferencia entre Bronce Clásico y Protocogotas. No cambia el patrón de asentamiento ni el funerario con o sin la presencia de cerámicas Cogotas cuya inclusión, muy reducida en los contextos analizados, arraigará en la Meseta redefiniendo motivos campaniformes (Delibes et al. 1990). Novedades como los enterramientos en vasija no se perpetúan, debiéndose entender únicamente como gestos a nivel intragrupal, de escasa repercusión y representatividad en el conjunto de la comunidad.

La heterogénea configuración de las comunidades de la Edad del Bronce puede estar detrás de esta pluralidad, así como su articulación como sociedades segmentarias (Díaz del Río 2001; Pérez Villa 2015). El abandono progresivo de poblados, la remodelación de otros tantos, incluyendo la larga presencia del Campaniforme en varios de ellos, a la vez que se fundan nuevas instalaciones y se reocupan espacios ya habitados con anterioridad, determina una heterogénea transición entre comunidades Calcolítico - Bronce (Barroso 2016). Todo ello implica agregaciones y escisiones de población con cierta independencia, aperturas, cambios y permanencias con distinto grado de aceptación y desarrollo entre los que deben entenderse los enterramientos en urna.

\section{Agradecimientos}

El trabajo se inscribe dentro de los proyectos CCGC2014/027 de la UAH y 2019598/ JCCM-Arqueologia-2015. Luis Moreno Estefanel y Oscar Cambra (UAM) se encargaron del estudio del material antropológico junto a uno de los firmantes (A. González). Verónica Estaca y José Yravedra (UCM) estudiaron los restos faunísticos. A todos ellos les agradecemos que se ajustaran al corto plazo de tiempo que nos exigía la Administración. En el acceso a los fondos del Museo de Santa Cruz de Toledo siempre contamos con las facilidades de Jaime Galamillo y Jacobo Fernández. En el Museo Provincial de Guadalajara contamos con la ayuda de Miguel Angel Cuadrado. A José María Barco y Mariángeles Lancharro (UAH), les agradecemos su ayuda en el estudio de los materiales y su reproducción gráfica. 


\section{BIBLIOGRAFÍA}

Abarquero, F.J. (2012): “Cogotas I más allá del territorio nuclear. Viajes, bodas, banquetes y regalos en la Edad del Bronce peninsular", en J.A. Rodríguez Marcos y J. Fernández Manzano (eds.), Cogotas I. Una cultura de la Edad del Bronce en la Península Ibérica: 59110. Valladolid, Universidad de Valladolid.

Aliaga, R. (2012): Sociedad y Mundo Funerario en el III y II Milenio a. C. en la Región del Jarama. Tesis Doctoral, Universidad Autónoma de Madrid. Disponible en: https://repositorio.uam.es/ handle/10486/660395.

Aliaga, R. y Megías, M. (2011): Los Berrocales: un yacimiento de la Edad del Bronce en la confluencia Manzanares-Jarama. Patrimonio Arqueológico de Madrid 8. Madrid, Universidad Autónoma de Madrid.

Almagro Basch, M. (1960): "Hallazgos arqueológicos de Villaverde". Memorias de los Museos Arqueológicos Provinciales XVI-XVII (1955/57): 5-29.

Aranda, G. (2010): "Entre la tradición y la innovación: El proceso de especialización en la producción cerámica argárica”. Menga 01: 77-95.

Aranda, G. y Esquivel, J.A. (2007): "Poder y prestigio en las sociedades de la cultura de El Argar. El consumo comunal de bóvidos y ovicápridos en los rituales de enterramiento". Trabajos de Prehistoria 64,2: 95-118. DOI: http://dx.doi.org/10.3989/ tp.2007.v64.i2.111.

Aranda, G.; Montón-Subías, S. y Sánchez Romero, M. (eds.) (2015): The Archaeology of Bronze Age Iberia: Argaric Societies. Routledge Studies in Archaeology 17. Oxford, Routledge.

Bacvarov, K. (2008): “A long way to the West: earliest jar burials in Southeast Europe and the Near East", en K. Bacvarov (ed.), Babies Reborn: Infant/ Child Burials in Pre- and Protohistory. British Archaeological Report, International Series 1832: 61-70. Oxford, Archaeopress.

Baquedano, M. I.; Blanco, J. F.; Alonso P. y Álvarez, D. (2000): El Espinillo, un yacimiento calcolítico y de la Edad del Bronce en las terrazas del Manzanares. Arqueología, Paleontología y Etnografía 8. Madrid, Comunidad de Madrid.

Barroso, R. (2016): "Solo contrastando: Calcolítico $v s$. Bronce en la prehistoria del interior peninsular. ARPI 04 Extra: 264-285. 2016: http:/www.arqueologiaprehistorica.es/revistas/arpi\%2004-18.pdf .

Barroso, R.; Bueno, P.; González, A.; Candelas, N.; Rojas, J.M. y López, J.A. (2014): "Enterramientos de la Edad del Bronce en la Meseta Sur peninsular a partir del Sector 22, Yuncos (Toledo)”. Munibe 65: 117-136.

Blasco, C. (1997): "Manifestaciones funerarias de la Edad del Bronce en la Meseta". Sagvntvm 30: 173-190.

Blasco, C. (2012): "Cogotas I en la Meseta española", en J.A. Rodríguez Marcos y J. Fernández Manzano (eds.), Cogotas I. Una cultura de la Edad del Bronce en la Península Ibérica: 187-218. Valladolid, Universidad de Valladolid.

Blasco, C.; Montero, I. y Flores, R. (2016): “Bell Beaker funerary copper objects from the center of the Iberian Peninsula in the context of the Atlantic connections", en E. Guerra y C. Liesau (eds.), Analysis of the Economic Supporting the Social Supremacy the Beaker Groups. Proceedings of the XVII UISPP World Congress: 19-35. Burgos (2015), Oxford, Archaeopress publishing LTD.

Blasco, C.; Sánchez Capilla, M.L.; Calle, J.; Robles, F., González, V.M. y González, A. (1991): “Enterramientos del Horizonte Protocogotas en el valle del Manzanares". Cuadernos de Prehistoria y Arqueología de la Universidad Autónoma de Madrid 18: 55-11.

Brück, J. (1999): "What's in a settlement? Domestic practice and residential mobility in Early Bronze Age southern England", en J. Brück y M. Goodman (eds.), Making places in the prehistoric world: Themes in settlement archaeology: 52-75. London, UCL press.

Bueno, P.; Barroso, R. y Balbín, R. (2008): "Campaniforme en las construcciones hipogeas del megalitismo reciente al interior de la Península Ibérica". Veleia 24-25: 771-790.

Colomer, L. (2005): “Cerámica prehistórica y trabajo femenino en el Argar: una aproximación desde el estudio de la tecnología cerámica”, en M. Sánchez Romero (coord.), Arqueología y género: 177-217. Granada, Universidad de Granada.

Contreras, F.; Cámara, J.A.; Robledo, B. y Trancho, G. (2000): "La necrópolis del poblado de Peñalosa", en F. Contreras (coord.), Análisis histórico de las comunidades de la Edad del Bronce del Piedemonte meridional de Sierra Morena y Depresión LinaresBailén. Proyecto Peñalosa: 287-324. Arqueología. Monografía 10. Sevilla, Dirección General de Bienes Culturales.

Contreras, F. y Alarcón, E. (2012): "La cultura de Cogotas I y las comunidades argáricas del Alto Guadalquivir", en J.A. Rodríguez Marcos y J. Fernández Manzano (eds.), Cogotas I. Una cultura de la Edad del Bronce en la Península Ibérica: 165-186. Valladolid, Universidad de Valladolid. 
Delibes, G. (1971): “Una necrópolis de inhumación individual de la Edad de Bronce en Villalmanzo (Burgos)". Boletín del Seminario de Arte y Arqueología XXXVII: 407-416.

Delibes, G.; Fernández, J. y Rodríguez, J.A. (1990): "Cerámica de plenitud de Cogotas I: el yacimiento de San Román de la Hornija (Valladolid)". Boletín del Seminario de Estudios de Arte y Arqueología 56 : 64-59.

Díaz del Río, P. (2001): La formación del paisaje agrario: Madrid en el III y II milenios BC. Arqueología, Paleontología y Etnografía 9. Madrid, Comunidad de Madrid.

Díaz del Río, P.; Consuegra, S.; Peña, L.; Márquez, B.; Sampedro, C.; Moreno, R.; Albertini, D. y Pino, B. (1997): "Paisajes agrarios prehistóricos en la Meseta peninsular: el caso de Las Matillas (Alcalá de Henares, Madrid)". Trabajos de Prehistoria 54(2): 93-111.

Esparza, A., Velasco, J. y Delibes, G. (2012a): “HUM 2005-00139: Planteamiento y primeros resultados de un proyecto de investigación sobre la muerte en Cogotas I", en J.A. Rodríguez Marcos y J. Fernández Manzano (eds.), Cogotas I. Una cultura de la Edad del Bronce en la Península Ibérica: 259-320. Valladolid, Universidad de Valladolid.

Flores, R. y Garrido, R. (2014): "Campaniforme y conflicto social: Evidencias del yacimiento de Humanejos (Parla, Madrid)", en Actas de las novenas Jornadas de Patrimonio Arqueológico en la Comunidad de Madrid: 159-167. Madrid (2012), Madrid, Comunidad de Madrid.

Gil, J.I.; Menéndez, M.L.; Reyes, F. y Reyes, J.L. (1988): "Excavaciones en el yacimiento del Bronce Medio del Cerro del Obispo, Castillo de Bayuela (Toledo)", en Congreso de Historia de Castilla - La Mancha. T. III: 93-100. Ciudad Real (1985), Ciudad Real, Junta de Comunidades de Castilla-La Mancha.

González Martín, A. (2008): "Mitos y realidades entorno a la excavación, el tratamiento y el estudio de los restos arqueológicos no adultos", en S. Muriel; C. Olaria y F. Gusi, (coords.), Nasciturus; infans, puerulus. Vobis mater terra. La muerte en la infancia: 57-76. Castellón, Diputación Provincial de Castellón.

Gusi, F. y Luján, J. (2011): “Enterramientos infantiles y juveniles durante la edad del bronce peninsular: una aproximación cuantitativa". Quaderns de Prehistòria i Arqueología de Castelló 29: 153-208.

Hernández Pérez, M. S. (2009): "Tiempos de cambio. El final del Argar en Alicante", en M.S. Hernández
Pérez; J.A. Soler Díaz y J.A. López Padilla (eds.), En los confines del Argar. Una Cultura de la Edad del Bronce en Alicante: 292-305. Alicante, Museo Arqueológico de Alicante.

Hernández Pérez, M.S. (2012): “El Cabezo Redondo (Villena, Alicante) y el Bronce Tardío en las tierras meridionales valencianas", en J.A. Rodríguez Marcos y J. Fernández Manzano (eds.), Cogotas I. Una cultura de la Edad del Bronce en la Península Ibérica: 111-146. Valladolid, Universidad de Valladolid.

Kunter, M. 2000: “Los restos de esqueletos humanos hallados en Fuente Álamo durante las campañas de 1985,1988 y 1991", en H. Schubart; V. Pingel y O. Arteaga (eds.), Fuente Álamo. Las excavaciones arqueológicas 1977-1991 en el poblado de la Edad del Bronce: 265-283. Sevilla, Junta de Andalucía, Consejería de Cultura.

Lorenzo, J.I. y Borobia, E.L. (2000): "Restos óseos humanos”, en M.I. Baquedano; J.F. Blanco; P. Alonso y D. Álvarez (eds), El Espinillo, un yacimiento calcolitico y de la Edad del Bronce en las terrazas del Manzanares. Arqueología, Paleontología y Etnografía 8: 137-140. Madrid, Comunidad de Madrid. Anexo 1.

Lull, V. y Estévez, J. (1986): “Propuesta metodológica para el estudio de las necrópolis argáricas", en $\mathrm{Ho}$ menaje a Luís Siret: 441-452. Cuevas de Almanzora (1985), Sevilla, Junta de Andalucía.

Lull, V.; Micó, R.; Rihuete, C. y Risch, R. (2004): “Las relaciones de propiedad de la sociedad argárica. Una aproximación a través del análisis de las tumbas de individuos infantiles”. Mainake XXVI: 233-272.

Lull, V.; Micó, R.; Rihuete, C. y Risch, R. (2011): "Proyecto La Bastida": economía, urbanismo y territorio de una capital argárica". Verdolay 13: 5770.

Lull, V.; Micó, R.; Rihuete, C.; Risch, R.; Celdrán, E.; Fregeiro, M.I.; Oliart, C. y Velasco, C. (2015): La Almoloya (Pliego, Murcia). Ruta argárica. Guías arqueológicas 2. Bullas, Integral

Martínez, A.; Ponce, J. y Ayala, M.M. (1996): Las prácticas funerarias de la cultura argárica en Lorca - Murcia. Lorca, Ayuntamiento de Lorca y Caja Murcia.

Martínez Navarrete, M.I. (1988): La Edad del Bronce en la Submeseta Suboriental. Serie Tesis doctorales. Madrid, Universidad Complutense.

Mc George, P.J.P. (2012): "The Petras intramural infant jar burial: context, symbolism, eschatology", en M. Tsipopoulou (ed.), Petras, Siteia- 25 years of excavations and studies. Monographs of the Danish 
Institute at Athens Volume 16: 291-302. Athens, The Danish Institute at Athens.

Menéndez, M.; Gil, J.I.; Reyes, F. y Reyes, J.L. (1988): "Tipología del material procedente de la necrópolis del bronce medio de El Cerro del Obispo. Castillo de Bayuela. Toledo", en Congreso de Historia de Castilla - La Mancha. T. III: 101-111. Ciudad Real (1985), Ciudad Real, Junta de Comunidades de Castilla-La Mancha.

Nájera, T.; Molina, F.; Jiménez, S.; Sánchez Romero, M.; Al Oumaoui, I.; Aranda, G.; Delgado, A. y Laffranchi, Z. (2010): "La población infantil de la Motilla del Azuer: Un estudio bioarqueológico". Complutum 21-2: 69-102.

Orrelle, E. (2008): "Infant Jar Burials a ritual associated with early agriculture?", en K. Bacvarov (ed.), Babies Reborn: Infant/Child Burials in Pre- and Protohistory. British Archaeological Report, International Series 1832: 71-78. Oxford, Archaeopress.

Perera, J.; Garrido, G.; Pérez, J. y Rojas, J.M. (2010): "La excavación arqueológica en el yacimiento Las Mayores en Numancia de la Sagra (Toledo). Campaniforme y Bronce en la Comarca de la Sagra", en Actas de las II Jornadas de arqueología de Castilla-La Mancha Vol. 1: 1-32 CD Toledo (2007), Toledo, Diputación Provincial.

Pérez de Barradas, J. (1936): "Nuevos estudios sobre Prehistoria Madrileña I. La colección Bento". Anuario de Prehistoria Madrileña IV-V-VI, 19331935: 1-90.

Pérez Villa, A. (2015): Pautas funerarias y demográficas de la Edad del Bronce en la cuenca media y alta del Tajo. Bibliotheca Praehistorica Hispana 31. Madrid, CSIC.

Ríos, P.; Blasco, C. y Aliaga, R. (2012): "Entre el Calcolítico y la Edad del Bronce. Algunas consideraciones sobre la cronología campaniforme". Cuadernos de Prehistoria y Arqueología de la Universidad Autónoma de Madrid 37-38: 195-208.

Valiente, J. (1987): La Loma del Lomo I (Cogolludo, Guadalajara). Excavaciones arqueológicas en España 162. Madrid, Ministerio de Cultura.

Valiente, J. (1991): "Sobre enterramientos infantiles de la Edad de Bronce". Cuadernos de Prehistoria y Arqueología Castellonenses 15: 143-156.

Valiente, J. (1992): La Loma del Lomo II, Cogolludo (Guadalajara), Patrimonio y Arqueología 5. Toledo, Junta de Comunidades de Castilla-La Mancha.

Valiente, J. (1995): "El hábitat eneolítico de La Loma del Lomo (Cogolludo, Guadalajara)", en R. Balbín; J. Valiente y M.T. Mussat (coords.), Arqueología en Guadalajara: 137-149. Toledo, Junta de Comunidades de Castilla - La Mancha.

Valiente, J. (2001): La Loma del Lomo III (Cogolludo, Guadalajara). Patrimonio Histórico-Arqueología. Castilla-La Mancha. Toledo, Junta de Comunidades de Castilla-La Mancha.

Vega, J.; Herrera, M.T.; Méndez, J.C.; Carrasco, A.; Martín, C. y Montesino, L. (2014): "El Campaniforme del yacimiento "Arroyo de Humanejos-km 24, N-401", en Actas de las novenas jornadas de Patrimonio Arqueológico en la Comunidad de Madrid: 385-389. Madrid (2012), Madrid, Comunidad de Madrid.

Whittaker, H. (2014): Religion and Society in the Middle Bronze Age Greece. New York, Cambridge University Press.

Yravedra, J. y Estaca, V. (2013): “Anejo VII. Informe arqueozoológico”, en J. Morín y J. Rasero de Luján (eds.), Las producciones cerámicas en el territorio segobricense. Serie época romana/ Antigüedad tardía: 171-174. Madrid, MArq. Audema 